\section{Las hojas sabias en otra casa. Análisis de la traducción de la Constitución Política colombiana a la lengua indígena inga}

\author{
The sage leaves in another house. Analysis \\ of the translation of the Colombian Constitution \\ to an indigenous language \\ Folhas sábias em outra moradia. Análise da \\ tradução da Constituição Política colombiana \\ para uma língua indígena
}

doi:Io.I I I44/Javeriana.SYP33-65.hsoc

\author{
Recibido: Marzo 27, 2014 \\ Aceptado: Julio 4, 2014 \\ Submission date: March 27, 2014 \\ Acceptance date: July 4, 2014
}

\section{Origen del artículo}

El artículo es producto de una iniciativa independiente del investigador, realizada de manera individual, sin contar con financiación externa. Las primeras observaciones y reflexiones se iniciaron en $201 \mathrm{I}$, para luego retomar el tema y la redacción en 2013.

Jean Paul Sarrazin

Colombiano. Antropólogo con opción en Filosofía (Universidad de los Andes). Magíster en Migraciones y Relaciones Interétnicas (Université de Poitiers). Doctor en Sociología (Université de Poitiers). Docente investigador vinculado al Departamento de Sociología de la Universidad de Antioquia, Medellín, Antioquia. Correo electrónico: jean.sarrazin@udea.edu.co 


\section{Resumen}

Este artículo ofrece una perspectiva crítica sobre el caso de la traducción de la Constitución Política de Colombia a la lengua indígena inga (del sur de Colombia). Se analiza específicamente el uso reiterado del concepto bien en dicha traducción. Este análisis lleva a reflexionar sobre la traducción en general como un acto creativo, cuyos posibles resultados no se pueden desligar de contextos sociohistóricos, económicos o políticos, considerando particularmente el marco de las políticas multiculturalistas y el ideal de "interculturalidad". De esta manera se subraya el papel fundamental de los traductores en las relaciones interétnicas, al influenciar las representaciones que se construyen sobre la sociedad mayoritaria, el Estado o sus instituciones. Se observa, además, que las traducciones constituyen mecanismos susceptibles de difundir conceptos y valores culturales funcionales a ciertas formas de dominación.

Palabras clave: traducción; interculturalidad; relaciones interétnicas; representaciones; valores culturales

\section{Abstract}

This article offers a critical perspective on the translation of the Political Constitution of Colombia to the Inga indigenous language (in southern Colombia). It is specifically analyzed the repetitive use of the concept bien (good) in this translation. This analysis allows us to reflect on the translation in general, as a creative act, whose possible outcomes cannot be separated from socio-historical, economic and political contexts, particularly considering the framework of multicultural policies and the ideal of "interculturality". Thus the key role of translators in interethnic relations is emphasized, in order to influence the representations that are built on mainstream society, the State and its institutions. It further notes that translations are mechanisms likely to disseminate concepts and functional cultural values to certain forms of domination.

Keywords: translation; interculturality; ethnic relations; representations; cultural values

\section{Resumo}

Este artigo oferece perspectiva crítica sobre o caso da tradução da Constituição Política da Colômbia para a língua indígena inga (do sul da Colômbia). Analisa-se especificamente o uso reiterado do concepto bem em tal tradução. Esta análise faz refletir sobre a tradução em geral como fato criativo, cujos possíveis resultados não podem se desligar de contextos sociohistóricos, económicos ou políticos, considerando particularmente o quadro das políticas multiculturalistas e o ideal de "interculturalidade". Desta maneira remarca-se o papel fundamental dos tradutores nas relações interétnicas, ao influenciar as representações construídas sobre a sociedade majoritária, o Estado ou suas instituições. Observa-se, aliás, que as traduções constituem mecanismos susceptíveis de difundir conceitos e valores culturais funcionais a certas formas de dominação. Palavras-chave: tradução; interculturalidade; relações interétnicas; representações; valores culturais 
Jean Paul Sarrazin

\section{Las hojas sabias en otra casa. Análisis de la traducción de la Constitución Política colombiana a la lengua indígena inga}

\section{Introducción}

Las reflexiones presentadas aquí a manera de ensayo surgen del análisis de "La Constitución Política de Colombia en inga" (CCELA, I994a) ${ }^{\mathrm{r}}$, donde se examina particularmente el uso del término bien y otros adjetivos o adverbios semánticamente relacionados (como buen o bueno). El uso de este tipo de términos valorativos en dicho texto llama la atención porque los pasajes que se tradujeron de la Constitución Política —en su versión original en castellano- no contienen las palabras bien, buen, bueno ni similares formas lingüísticas que explícitamente evoquen juicios de valor. Así, este artículo se basa en el análisis de extractos de la traducción al inga, en la cual los conceptos propios del Estado y su legislación fueron traducidos utilizando términos o expresiones nativas con cargas valorativas evidentes. Tratar de comprender las razones e implicaciones del uso repetido de dichos términos constituye, entonces, la motivación original de este estudio.

El proyecto de traducción se llevó a cabo entre i99i y ig93 en el marco de políticas multiculturalistas del Estado, basándose en principios como el respeto y la protección de la diversidad cultural y lingüística. Sin entrar en detalles sobre el marco histórico y jurídico en el que se desarrolló este proceso (Landaburu, I997a; Oróstegui, 2008), notaremos fundamentalmente que la Constitución de I99I afirma: "El Estado reconoce la diversidad étnica y cultural de la Nación Colombiana” (art. 7); "el Estado reconoce la igualdad y dignidad de todas las [culturas] que conviven en el país" (art. 70); "las lenguas y dialectos de los grupos étnicos son también oficiales en sus territorios" (art. Io); "los integrantes de los grupos étnicos tendrán derecho a una formación que respete y desarrolle su identidad cultural" (art. 68). Adicionalmente, el artículo 4I establece que "el Estado divulgará la Constitución" y "en todas las instituciones de educación [incluso las que existan dentro de las comunidades indígenas], oficiales o privadas, será obligatorio el estudio de la Constitución”.

Más específicamente, el proyecto de traducción de la Constitución Política se inscribe en lo que podemos llamar el ideal de interculturalidad. Si el multiculturalismo puede definirse — de manera muy resumida- como un conjunto de políticas que reconocen la existencia de diferentes culturas que viven en un país, la inter- 
culturalidad remite a "lo que sucede cuando los grupos entran en relaciones e intercambios" (GarcíaCanclini, 2005, p. 15). Puesto que los grupos que se relacionan en la interculturalidad suelen hablar lenguas diferentes, sus intercambios lingüísticos los pueden hacer a través de una lingua franca, o por medio de traductores. El uso de una lingua franca es frecuentemente criticado, ya que implica la imposición de una lengua dominante (el castellano, en el caso colombiano, o el inglés, en el mundo globalizado actual). Recurrir a las traducciones, en cambio, supone el respeto de cada una de las lenguas. Sin embargo, como veremos, las traducciones también hacen parte de las relaciones de poder en que se mueven los grupos sociales concernidos.

Así, el análisis de un ideal relativamente simple, como es el de facilitar el acceso a las leyes del Estado en las lenguas indígenas, nos llevará a una reflexión crítica sobre el papel de la traducción en el multiculturalismo y dentro del ideal de interculturalidad (cuyas características más específicas serán descritas más adelante). Adicionalmente, esta discusión nos conduce a una reflexión más general sobre las condiciones para que los individuos de un país culturalmente diverso, como Colombia, pue- dan entender a cabalidad el sentido de un concepto político-administrativo o de una ley.

En su realización práctica y en la concreción de sus resultados, el proyecto de traducción de la Constitución se enfrentaba a una problemática nada simple. Como advirtió el entonces director del Centro Colombiano de Estudios de Lenguas Aborígenes (CCELA) de la Universidad de los Andes: “... buscar en estas lenguas [los] equivalentes de expresiones y términos jurídicos propios de la tradición urbana, escrita, europea representaba una tarea totalmente nueva y un desafío muy arriesgado" (Landaburu, I997a, p. II I). Por demás, había que desarrollar un "género discursivo con expresiones relativas a realidades nuevas" (Rojas, 200I, p. 363). Se trata, efectivamente, de un caso en el cual existe una distancia cultural considerable entre la lengua de partida y la lengua de llegada (el castellano y el inga, respectivamente), y en el que no hay, en la sociedad de la lengua de llegada, situaciones similares a las referidas en el texto original.

Vemos, pues, que el equipo a cargo del proyecto aceptó un formidable reto, sin poder anticipar precisamente cuáles serían sus resultados y, mucho menos, sus consecuencias sociales. Entre 
las estrategias utilizadas por los traductores para dar a entender el sentido de los conceptos políticoadministrativos y las leyes estatales, se puede observar no solo el repetido uso del concepto bien (y los términos relacionados semánticamente), sino también las comparaciones o las referencias a mitos y otros elementos propios del medio en el que tradicionalmente ha vivido la comunidad indígena. Es así como, por ejemplo, la palabra Constitución fue traducida en algunas partes del texto como "las hojas sabias".

Es importante destacar también que el texto objeto de la traducción es de una naturaleza especial. En efecto, la Constitución no es un conjunto de enunciados neutrales o de instrucciones técnicas y, además, "no estamos ante un texto descriptivo, sino ante un texto normativo y además performativo [...] que busca instaurar la norma" (Landaburu, I997b, p. ı66). Hay que añadir a esto, y de manera central en el presente análisis, que si todas las normas surgen de juicios de valor, la Constitución Política estaría repleta de estos (aunque sean tácitos en la mayoría de los casos). ¿Significa esto que la traducción de la Constitución debería contener expresiones lingüísticas con juicios de valor?

Por otro lado, considerando que se trata de una normatividad proveniente de una sociedad dominante con respecto a la sociedad indígena, cabe preguntarse de qué manera puede haber influido en la traducción esta situación de dominación-marginalización (situación propia también del proyecto de "interculturalidad" en Colombia). Justamente, podemos analizar este caso a la luz del concepto politics of translation (Spivak, 200o), entendiéndolo como las relaciones de poder que acompañan la práctica misma de traducir.

Debemos partir del hecho de que no existe una sola, única y verdadera traducción de un texto, sino que cada traducción es un acto creativo que recurre a adjetivos y adverbios inusitados, metáforas, paráfrasis o imágenes particulares. Por eso, se propone acá un examen detallado de algunas de las estrategias puestas en práctica por los traductores para transmitir un supuesto sentido de los artículos constitucionales. Para comenzar este análisis enunciaremos algunos aspectos de la situación en la que surgió el proyecto de traducción de la Constitución, así como algunas de las problemáticas generales que atañen a toda práctica de traducción. Posteriormente se presentarán algunos ejemplos del texto analizado, de manera que el lector pueda apreciar concretamente el origen de la presente reflexión. En una última sección se interpretarán estos ejemplos de la traducción a la luz de elementos estructurales que influyen en la relación entre los indígenas, el Estado y la sociedad mayoritaria, y se abordará más en detalle el marco de la interculturalidad en cuanto proyecto concebido por las élites intelectuales del país.

\section{Problemáticas de la traducción como acto creativo}

Es importante señalar de antemano que las distintas traducciones de la Constitución Política a lenguas vernáculas son producto de investigaciones etnolingüísticas rigurosas, realizadas conjuntamente por académicos de tradición occidental y por indígenas, luego de largas discusiones, y con el aval de las autoridades tradicionales respectivas (Landaburu, I997a, pp. II2-II4). Además de la producción de los textos, el proyecto buscó propiciar una reflexión colectiva sobre las relaciones entre las comunidades indígenas y el Estado (Landaburu, I997a). Sin embargo, como fue claro para el coordinador del proyecto, tal ejercicio debía diferenciarse de la traducción misma, ya que, de otra manera, un texto como tal nunca habría podido ser finalizado.

El proyecto de traducción favoreció la creación de formas de escritura en lenguas que no la tenían hasta entonces. Igualmente, este proyecto permitió el enriquecimiento del léxico de estas lenguas en áreas, como las matemáticas, las ciencias o la jurisdicción occidentales (Landaburu, 2004), al crear conceptos que no existían en el universo semántico indígena. No obstante, hoy debemos preguntarnos concretamente cuáles son esos nuevos conceptos que se crean, por qué se crean y cuáles son sus implicaciones. 
Se ha asumido, además, que gracias a este tipo de iniciativas de traducción se podrán establecer canales de comunicación para la construcción de relaciones más igualitarias entre los indígenas, la sociedad mayoritaria ("blanca" o "mestiza") y el Estado, para así fortalecer el proyecto de "interculturalidad" en el país. Pero, como se discutirá, las relaciones interétnicas y las traducciones que están de por medio remiten a problemáticas muy complejas, en las cuales la igualdad es más un horizonte que una realidad.

En lo que respecta a todo proceso de traducción, hay que recordar que este no es un simple ejercicio para encontrar equivalencias mecánicamente. En efecto, ninguna traducción es la correspondencia exacta del original, como se creía antiguamente (Torres, 2002, p. 5), o como muchos funcionarios bajo las políticas multiculturalistas parecen seguir creyendo. La verdad es que el acto de traducir nunca es una transferencia transparente de significado, y no todos los conceptos de una cultura son traducibles a otra (Bassnett, 2002, p. 38; Kamler \& Threadgold, 2003, p. 150). Así, las traducciones de las que dependen los intercambios en la multiculturalidad nunca deben ser consideradas como el reemplazo de unos significantes por otros para designar significados que, supuestamente, serían comunes a todas las partes.

Esta situación debe ser enunciada de antemano, ya que afecta el resultado de cualquier traducción. En vez de hablar de la traducción como si fuera un simple ejercicio mecánico, conviene hablar de los traductores: seres humanos inmersos en la complejísima red de relaciones, acciones y reacciones que llamamos sociedad; personas cuyo objetivo es transmitir conceptos, sentidos, formas de concebir la realidad específicas a cada grupo cultural. En efecto, los signos lingüísticos hacen referencia a una realidad cultural vivida por los hablantes de la lengua, quienes están inmersos en un medio y una estructura social que son el resultado de procesos históricos particulares. Por eso, el traductor tiene que recurrir a un vasto conjunto de conocimientos que van más allá del campo estrictamente lingüístico (Brennan, 200I), conocimientos que pueden variar de un individuo a otro, o de una circunstancia a otra.

Por otro lado, hay que tener en cuenta que los términos utilizados en cada lengua pueden tener "significados asociativos" (Bassnett, 2002, p. 39), los cuales varían de una comunidad lingüística a otra, de un momento histórico a otro. Dentro de los significados asociativos de una palabra podemos encontrar, por ejemplo, las connotaciones, las referencias a vivencias pasadas, las imágenes o emociones evocadas, así como las conjeturas o los juicios de valor que surgen de todo ello. El traductor debe tener en cuenta estas asociaciones evocadas, al igual que las sutiles reglas de uso de cada palabra, todo lo cual implica conocer bien los dos contextos sociolingüísticos en cuestión.

Pero dicho conocimiento se combina con la imaginación: el traductor es un autor que crea un nuevo texto (Paz, I97I). La traducción, en cuanto "práctica de resignificación" (Kamler \& Threadgold, 2003, p. 150), supone a la vez una pérdida y una ganancia semántica inherentes al acto de creación del traductor. Por eso, el objeto de nuestro análisis debe ser, como lo plantea Howland (2003, p. 56), el proceso de construcción de significados que ocurre en la acción misma de traducir.

El significado de las palabras depende de sus relaciones (y distinciones) con otros elementos que componen las experiencias vivenciales de los sujetos. A su vez, los conceptos así constituidos suelen hacer parte de una cierta jerarquía (Graeber, 2005, p. 449), puesto que están asociados a valores, es decir, a nociones sobre el bien, lo bueno, lo sublime, lo correcto, lo deseable, lo importante, lo conveniente, etc. (Graeber, 2005, p. 439). Debido a que los conceptos están intrínsecamente vinculados a los valores, el antropólogo Louis Dumont (citado por Graeber, 200I, p. I8) propuso acertadamente el concepto analítico ideas-valores. Utilizaremos entonces este concepto antropológico al analizar el caso de la traducción al inga, con el fin de identificar las ideas-valores que fueron articuladas por los traductores a la hora de presentar al Estado y su Constitución Política en ciertos términos. 
Etimológicamente, el verbo latino traducère ("traducir"), supone "llevar de un lugar a otro". El proyecto de la traducción de la Constitución es un ejemplo de tal "traslación", la cual implica llevar un texto normativo (y cargado de valores implícitos) a "otro lugar", introduciendo este complejo conjunto de conceptos y leyes dentro de una nueva "casa" (Landa, 2005) ${ }^{2}$, en este caso, la de una comunidad indígena. Para lograrlo, los traductores aspiran a crear un texto que sea comprensible y que parezca "familiar" para sus lectores. Pero - como veremos más adelante-crear dicha "familiaridad" y lograr tal adaptación a una nueva "casa" no son acciones anodinas, particularmente cuando implican la traslación de ideas-valores en un contexto de relaciones asimétricas de poder entre los grupos sociolingüísticos.

Para ilustrar todas estas problemáticas de la traducción, veamos con ejemplos concretos el material que dio origen a esta reflexión. Allí se pueden apreciar las estrategias lingüísticas utilizadas en tan compleja y delicada "mudanza".

\section{Algunas de las evidencias y cómo se llegó a ellas}

En esta sección se presentan algunos pasajes de la Constitución Política de Colombia en inga en los cuales aparecen términos como bien o bueno. Aunque en esta sección nos concentramos en el análisis semántico, es a partir de este tipo de evidencias como se hará una reflexión más general en las secciones posteriores del presente artículo, considerando el marco de las relaciones entre los indígenas, el Estado y la sociedad mayoritaria, lo cual ayuda a explicar las expresiones lingüísticas.

Pero para hacer una lectura de dichos ejemplos concretos, algunas precisiones técnicas son de rigor. En cada uno de los extractos transcritos a continuación, figura primero el artículo o palabra del original de la Constitución, a la cual llamaré la versión "Castellano I". En segunda instancia, se encuentra la versión en lengua inga segmentada en sus unidades significativas, morfema por morfema, lo cual está escrito usando el alfabeto cas- tellano (en cursivas) ${ }^{3}$. Posteriormente figuran los morfemas segmentados traducidos al castellano. Y, finalmente, encontramos la traducción al castellano desde la versión en inga, traducción que llamaré "Castellano 2" (entre comillas y en cursivas). En la mayoría de casos, luego de estas transcripciones selectas, presento algunos de mis comentarios puntuales al respecto.

Es principalmente a partir de la comparación entre las versiones "Castellano I" y "Castellano 2" como podemos apreciar más claramente la diferencia entre la versión de la lengua de origen y la versión de la lengua de llegada, para así analizar el aporte que hicieron los traductores en su esfuerzo por transmitir el sentido de la Constitución, readaptándolo al universo semántico inga, y utilizando términos relacionados con un concepto claramente valorativo y normativo como es el de bien ${ }^{4}$. Aunque en el estudio que dio origen al presente artículo se analizaron las traducciones de ocho "palabras importantes" y de I7 artículos de la Constitución, a continuación solo se presentan algunos ejemplos relevantes.

\section{Traducción de algunas "palabras importantes"}

Comenzaremos con la única excepción a la regla metodológica descrita en la sección anterior: aunque la traducción de la palabra Constitución no contenga ninguna de las partículas relativas al concepto bien o sus equivalentes, es importante considerar este ejemplo, puesto que ayuda a entender cuál es la categoría y el estatus que se le da en inga a la Carta Magna.

\section{- Constitución \\ Achka iachag panga kuna \\ // bastante/sabio-agente/hoja-plural// \\ "la ley que guía las demás leyes"}

A propósito de la traducción de esta palabra, cabe notar que no se traduce como algo ajeno o distanciado de la normatividad y las referencias propias del universo semántico inga. En efecto, si se considera que la Constitución es "la ley que 
guía las demás leyes", se puede asumir que aquella también marcaría la pauta de las leyes ingas. Así, los traductores recurrieron a un conjunto de palabras para construir una primera idea-valor asociada a la Constitución.

Más adelante, en otros pasajes de la traducción, también se evidencia que se le ha dado una connotación positiva al documento constitucional en general, puesto que se traduce como "las hojas sabias". Todo lo anterior puede ser importante para entender el frecuente uso del concepto bien en las traducciones de otras palabras y de los artículos.

\section{- Política \\ Runakunata uma kawag \\ //persona-plural-acusativo/bien/ver-agente// \\ "la que vela por el bienestar"}

No es necesario entrar en las múltiples controversias sobre el concepto de lo político en el mundo occidental para notar que esta traducción de la palabra es sorprendentemente sesgada hacia una versión positiva de la cuestión.

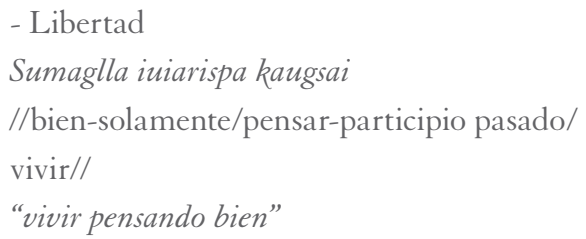

La asociación entre bien y libertad que se manifiesta acá es interesante y remite a profundos debates filosóficos que pueden cuestionar una cierta definición moderna e individualista de la libertad. En otras partes de la traducción se observa una estrecha relación entre el bien y lo comunitario, y no hay referencias a un bien individualizado: no existe diferencia entre el bien para el individuo y el bien para la comunidad, lo que hace que esta noción de libertad sea radicalmente distinta de lo que comúnmente denota el término en nuestras sociedades modernas.

- Economía

Llagtapi tukuikunamanda suma kaugsangapa tiaska //nación/todo-plural-de procedencia/bien/

vivir para/hay- participio pasado//

"todo lo que hay en la nación para vivir bien"

- Plan de Desarrollo

Suma iuiarispa mirachii

//bien/pensar-gerundio/reunir//

"pensando en estar bien"

Las traducciones de Economía y Plan de Desarrollo presentan a estas formas de administración de los recursos (controladas, valga recordarlo, desde el exterior de las comunidades indígenas y también desde el exterior del país) como si fueran automáticamente maneras de "vivir bien" o "estar bien", lo cual oculta las controversias y críticas que existen alrededor de estos conceptos, por ejemplo, a propósito de las relaciones de poder y exclusión que allí operan.

Solo para mostrar cuánto puede variar la traducción de los mismos conceptos, la versión en kubeo de la Constitución (CCELA, i994b) traduce Economía como "valor de los bienes" (refiriéndose a los objetos en general), y Plan de Desarrollo como "encabezar para decir[:] así vamos a trabajar", es decir, decidir un plan de actividades colectivas.

\section{Traducción detallada de algunos artículos ${ }^{5}$}

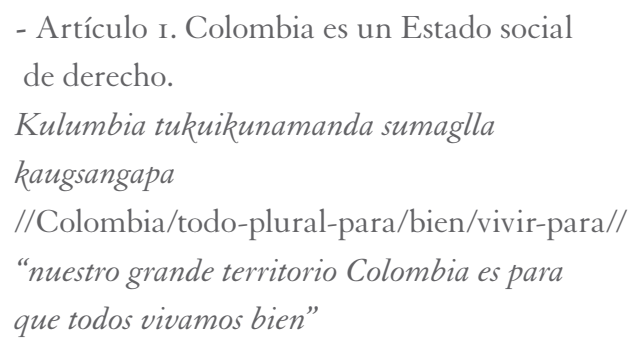

- Artículo i. Colombia es un Estado social de derecho.

Kulumbia tukuikunamanda sumaglla

kaugsangapa

//Colombia/todo-plural-para/bien/vivir-para//

"nuestro grande territorio Colombia es para

que todos vivamos bien"

Es difícil establecer a qué corresponde la noción de bien en la versión original de esta frase primordial de la Constitución. Podemos encontrar una pista en las traducciones de las palabras Estado social y derecho por aparte, ya que en ambas existe la unidad inga sumaglla. Estado social se traduce como "la organización 
suprema de derecho del territorio que garantiza el bienestar", mientras que Derecho se traduce como "las condiciones para vivir en comunidad". Ello implica que Colombia se define como un ente que proporciona "bienestar" y las "condiciones para vivir en comunidad", sin que se explique que esto, más que la descripción de una realidad, es un ideal.

- Artículo 2. Son fines esenciales del Estado: servir a la comunidad, promover la prosperidad general y garantizar la efectividad de los principios, derechos y deberes consagrados en la Constitución; facilitar la participación de todos en las decisiones que los afectan y en la vida económica, política, administrativa y cultural de la Nación; defender la independencia nacional, mantener la integridad territorial y asegurar la convivencia pacífica y la vigencia de un orden justo.

[...] derechos y deberes consagrados en la Constitución $\lceil\ldots]$

imasa nukanchi sumaglla kaugsangasina

//como/nosotros/bien/vivir-como//

"para vivir bien nosotros, como está escrito en las hojas sabias"

[...] facilitar la participación de todos en las decisiones que los afecten y en la vida económica $[. .$.

tukuikuna agllai pudingapa nukanchimanda mas suma kaskata, Atun Llagtapi tukuikunamanda suma kuagsangapa sugkunalla charinakura

//todo-plural/escoger/poder-para/nosotros-para/más/ mejor/es-participio pasado acusativo/grande/territorioen/todos-para/bien/vivir-para/solamente unos/posees// "todos podemos escoger cualquier cosa mejor para nosotros, todo lo que hay en la Nación para poder vivir bien”

[...] política, administrativa y cultural de la Nación [...] suma kawachu y suma kawachu

//bien/velar/y bien/mirar/todo//

"la persona que mira el territorio grande debe velar por todas las personas que viven con otra forma de vida"

De nuevo, la Constitución ("las hojas sabias") se entiende como un texto que habla de la manera como "nosotros" [los ingas] podemos "vivir bien". Por otro lado, "la participación" que el Estado presumiblemente promueve, significa "escoger [lo] mejor". La administración estatal se presenta como algo intrínsecamente bueno y que se relaciona con el verbo "velar" (vinculado a la partícula inga suma, denotando su valor positivo), es decir, con una acción cotidiana y propia de la vida comunitaria de los ingas.

- Artículo 4o. Todo ciudadano tiene derecho a participar en la conformación, ejercicio y control del poder político. Para hacer efectivo este derecho puede: [...] constituir partidos, movimientos y agrupaciones políticas sin limitación alguna; formar parte de ellos libremente y difundir sus ideas y programas. [...] Acceder al desempeño de funciones y cargos públicos [...].

[...] constituir partidos políticos, movimientos y agrupaciones políticas sin limitación alguna; formar parte de ellos libremente y difundir sus ideas y programas [...] nukanchipa alli iniaikunata kaugsachispa

//nosotros-posesivo/buen/pensamiento-plural-agente/ revivir- gerundio//

"mostremos reviviendo nuestro buen pensamiento a todos los habitantes de nuestro territorio, [a] cualquiera que quiera reunirse llamémoslo"

Una vez más se observa el vínculo entre "el bien” y la política: construir agrupaciones políticas estaría relacionado con el "bien", y concretamente con "lo que es mejor para todos". Además, los movimientos políticos se asocian a un "buen pensamiento" que se "revive" (refiriéndose a la tradición ancestral indígena).

[...] Acceder al desempeño de funciones y cargos públicos $[\ldots]$

ministiskami sumaglla kaugsangapa

//necesitar/muy bien/vivir-para//

"todas las personas nacidas y crecidas en Colombia, en lo que necesitamos para poder vivir bien, podemos tener".

De manera implícita, los cargos públicos existirían para "vivir bien". En la traducción de otros conceptos, las instituciones del Estado se 
asumen también como manifestaciones del "buen pensar" - entre otras cosas, porque son producto de "elecciones [por voto]", lo cual se produciría "pensando bien"-, con el objetivo de "conseguir lo más bueno para nosotros".

Estas resignificaciones son, por lo menos, problemáticas si se reconocen las características de la realidad política nacional, regional o local, en la cual están a la orden del día, entre otras, la corrupción y los intereses económicos ajenos a los de la comunidad.

- Artículo 7o. El Estado promoverá la investigación, la ciencia, el desarrollo y la difusión de los valores culturales de la Nación.

[...] imasa mas nukanchiiacha kangapa, chimi mas suma wiñachispa apasunchi $[$ [...

//conocimiento/como/más/nosotros inteligente ser-para/ así/más/bueno/incrementar-gerundio/llevaremos// "el territorio grande tiene que buscar cómo viven otras personas, cómo nosotros vamos a aprender más; así incrementaremos nuestro conocimiento, luego podemos mostrar a los otros cómo nosotros vivimos y qué pensamiento tenemos".

La promoción de la "investigación” se representa como aquello que va a permitir a los indígenas "aprender más", lo que presupone que la investigación llevada a cabo por institutos o programas estatales sería lo mismo que "incrementar el conocimiento" de una comunidad indígena. Paralelamente, "la difusión de los valores culturales de la Nación" se equipara a "mostrar a los otros cómo nosotros [los ingas] vivimos y qué pensamiento tenemos", definición que oculta los intereses políticos y económicos detrás de las decisiones sobre lo que se define como los "valores culturales de la Nación”.

- Artículo 72. El patrimonio cultural de la Nación está bajo la protección del Estado.

kawaspa sumaglla wakachinga

//mirar-gerundio/muy bien/guardas-futuro//

"el pensamiento y la vida de los de antes que hay en el territorio grande, la Nación guardará muy bien mirando".
Como en el comentario sobre el artículo anterior, el supuesto de que el "patrimonio cultural de la Nación" sea "el pensamiento y la vida de los de antes" recuerda que el concepto se entiende de una manera apolítica, ignorando los filtros ideológicos y las relaciones de poder que determinan lo que es llamado "patrimonio" en cualquier parte del mundo.

\section{Análisis en el contexto de la "interculturalidad"}

Es importante recordar que traducciones como las que hemos visto son manifestaciones culturales que surgen dentro de una configuración histórica, social y política a la vez particular y compleja, como lo son las políticas multiculturalistas y, más recientemente, el ideal (o la utopía, como lo llama Rappaport [2008]) de lo que ha sido llamado "interculturalidad".

En el momento en que el proyecto de traducciones de la Constitución se llevó a cabo, otros grupos indígenas de Colombia optaron por distintas estrategias de traducción, obedeciendo a orientaciones políticas particulares y tomando a veces posiciones más distanciadas y críticas con respecto a la Carta Magna. Por citar solo algunos ejemplos, los indígenas wayúu — de la región Caribe-, quienes han vivido una larga e intensa historia de contactos y conflictos con los colonizadores de origen europeo, decidieron no traducir la palabra Constitución, por lo que simplemente optaron por escribirla de otra manera: "konstitusion" (CCELA, I994c). Los kubeos — habitantes de la Amazonia-, con una historia de menor contacto con Occidente y, quizás por eso, en una posición de menor oposición o rechazo, tradujeron la palabra Constitución como "Libro del árbol de alimento para la vida" (CCELA, 1994b). Los wayúu quisieron dejar en claro que la Constitución es un texto con leyes que les son ajenas y optaron por no usar una expresión de su propia lengua para referirse a aquella, mientras que los kubeos decidieron usar un referente simbólico-mítico propio y claramente valorado. Por su parte, los nasas (del sur de los Andes colombianos), con una fuerte 
historia de construcción de movimientos sociales de resistencia, "no tradujeron —en un sentido estricto- la Constitución, sino que reimaginaron sus preceptos fundamentales desde el punto de vista Nasa, construyendo así una crítica Nasa del Estado colombiano" (Rappaport, 2008, p. 235). Para Rappaport, en este ejercicio de traducción, los nasas habrían reconceptualizado términos políticos clave, como Estado, justicia o autoridad desde su propio punto de vista, llegando a crear alternativas a los modelos existentes de nacionalidad y ciudadanía inspiradas en el pensamiento indígena.

Respecto al proyecto de las traducciones en general, los documentos de trabajo debían permitir a los hablantes de la lengua indígena "evaluar el trabajo, criticarlo, utilizarlo, apropiarse de él" (Rojas, 200I, p. 365). Sin embargo, como ya se problematizó, es importante distinguir analíticamente dos tipos de acción que en la práctica no pueden mezclarse: la acción de producir un texto de traducción, y las críticas que puedan surgir de este y/o del proceso de su realización. Un rechazo radical de todo uso del lenguaje indígena para entender en términos vernáculos los conceptos y preceptos del Estado occidental-moderno llevaría simplemente a la anulación misma de toda posible traducción.

Han sido muchas las bondades que se vislumbraron a propósito del proyecto de las traducciones. En principio, este proyecto debería permitir que los indígenas usen su lengua para conocer el funcionamiento del Estado e interactuar con él. $\mathrm{El}$ proyecto se ha visto también como una forma de luchar contra la imposición de una lengua dominante, imposición de origen colonial que obliga a los indígenas a aprender el castellano para ser escuchados.

Pero mucho más allá de estas posibilidades difícilmente controvertibles, el proyecto se asoció a la promoción de las lenguas nativas, lo cual sería un factor importante para preservar las "identidades" y las "culturas indígenas" (Jamioy, 1995). Por demás, la colaboración entre lingüistas de una tradición científica occidental e indígenas se ha considerado una actividad que valoriza la lengua indígena, proporciona confianza a los nativos sobre su "particularidad cultural" y "los anima a escudriñar su cultura" (Aguirre, I995, p. 38). De manera general, las traducciones han sido relacionadas con una serie de medidas tendientes a favorecer un "intercambio horizontal" y el "diálogo intercultural”. Así, por ejemplo, al hacer mención de este proyecto, Roberto Pineda (I997) consideró: “... esta situación ha podido estimular la lectura de la Constitución en algunos grupos étnicos; pero sobre todo tiene una significación simbólica que puede, si se continúa el esfuerzo, abrir paso a una reflexión sobre la práctica del multiculturalismo como proceso de diálogo entre culturas" (p. I25).

Por su parte, la interculturalidad puede ser idealizada como un proceso en el cual, "a partir del reconocimiento de la propia realidad y de la propia identidad, se tenga la posibilidad de conocer otras culturas, para de esta manera enriquecer lo propio" (CCELA, I987, p. 8I); o, como lo afirmó López (citado por Rappaport, 2008, p. 5), la interculturalidad sería "la apropiación selectiva de conceptos entre diferentes culturas para construir un diálogo pluralista entre iguales". Este tipo de ideales hace parte de la doxa pluralista de un sector de la población colombiana, particularmente entre las élites intelectuales citadinas (Sarrazin, 20I I, pp. 325-365), sector que tiene muy pocas relaciones de convivencia real con comunidades indígenas. Por eso, debemos analizar críticamente cuáles son los procesos reales que se llevan a cabo cuando se intenta establecer una relación interétnica "entre iguales", siendo la traducción una de las prácticas centrales en dichos procesos.

Si bien es cierto que el ejercicio de traducción puede dejar muchas enseñanzas y abre la puerta a múltiples experiencias, los efectos supuestamente contrahegemónicos, a favor de la igualdad o de la preservación de las identidades indígenas, etc., no pueden ser celebrados sin antes haberlos constatado y analizado cuidadosamente. De la misma manera, no debemos justificar unas acciones solo porque se inscriben en una interculturalidad idealizada. 
En cambio, podemos analizar el texto de la traducción como una de las acciones que efectivamente se han llevado a cabo en el marco del multiculturalismo, para luego examinar concretamente sus dificultades prácticas. Aunque todavía sea vista por muchos como un simple ejercicio técnico o una etapa que se supera rápidamente, la traducción tiene en realidad un papel fundamental en el desarrollo de las relaciones interétnicas y las problemáticas inherentes a la interculturalidad. Por eso, debemos ser conscientes de que aun a este nivel lingüístico no hay tal "intercambio entre iguales".

En el texto analizado podemos observar que se asocian sorprendentemente ciertas nociones de lo que es "bueno" en inga, con lo que la Carta Magna promulga, y se usa el lenguaje nativo para calificar de manera positiva las imaginarias acciones del Estado y su existencia misma: el sujeto "Estado" se representa como una entidad que garantiza el "vivir bien", que provee bienestar, que incluye de manera igualitaria a todos los grupos que viven dentro de su "territorio grande", etc.

¿Cómo explicar que se optara por tantas expresiones con cargas valorativas al referirse al Estado, sus leyes, sus instituciones, sus conceptos fundamentales como nación, economía o política? La estrategia usada por los traductores evidencia la intención de hacer de la Constitución un texto comprendido por los hablantes nativos, lo cual implicó, en este caso, que sus componentes fueran representados a través de referentes domésticos y conceptos propios de la tradición inga. En efecto, los traductores se vieron inclinados a presentar la Constitución como un conjunto de normas o principios que corresponden o equivalen al "buen pensamiento" tradicional; sus dictámenes se presentan en las mismas categorías de lo que es bueno para la comunidad inga y para toda persona en general, remitiendo además a una imagen nativa de sabiduría (las "hojas sabias"). Al ser relacionadas con el universo de ideasvalores inga, las imágenes positivas sobre el Estado, sus instituciones o los conceptos que lo fundamentan ideológicamente, pueden ser "domesticados" y aceptados de una manera mucho más directa.
Así, una traducción realizada dentro de los lineamientos de una política multiculturalista puede — paradójicamente - favorecer la penetración en las comunidades indígenas de conceptos y valores hegemónicos, los cuales, gracias a la utilización misma de las lenguas vernáculas, se presentan ante los hablantes nativos como si fueran parte de su propio lenguaje tradicional, recibiendo formas reconocidas y "familiares". Esta situación tiene paralelos: varios estudios recientes muestran que el multiculturalismo no necesariamente consigue los efectos imaginados por muchos de los intelectuales que lo defienden. Por ejemplo, la creación -bajo el actual régimen multiculturalista- de instituciones "indígenas" de salud, educación o autogobierno, lejos de favorecer la autonomía de las comunidades, como lo pretendían los discursos, en realidad han facilitado la penetración de lógicas estatales en dichas comunidades (Chaves, 20II). La argumentación del presente artículo muestra que dicha penetración podría ser facilitada aún más a través del uso de las lenguas nativas.

Vemos entonces claramente que traducir la Constitución no es simplemente un instrumento formal de transmisión de "datos" para los indígenas. Se trata de creaciones nuevas que buscan transmitir un sentido normativo y que surgen dentro de un cierto régimen. La ley y la autoridad tienen que encontrar formas de legitimidad simbólica. Recordemos también que una ley es el fruto de una forma de valoración. Debemos preguntarnos entonces hasta qué punto es posible transmitir el verdadero sentido de las leyes, con toda su carga semántica y valorativa, sin presentarlas a través de formas valorativas autóctonas, es decir, como expresiones propias de "lo bueno" y "lo que debe ser".

Guardando las proporciones, estamos frente a una problemática algo similar a la que se presenta al traducir un poema cuya versión original contiene pasajes considerados como "bellos" por sus lectores. En este caso es probable que los traductores intentarán producir un efecto estético similar en sus lectores, para lo cual remitirán a imágenes y a prácticas del mundo social en el que habitan los receptores del nuevo texto. Correspondientemente, 
la traducción de la Constitución puede tener como objetivo el trasladar una visión y un sistema de valores que sustentan las leyes allí expuestas. Por eso, cabe preguntarse si es realmente posible traducir palabras (para no hablar de frases y preceptos) como desarrollo, patrimonio, derecho, política, etc., sin recurrir a referencias propias del mundo, la forma de vida y las tradiciones de la población receptora.

Por otro lado, también debemos tener en cuenta que tradicionalmente entre los ingas la norma social y lo que es considerado como "bueno" en la vida cotidiana no están necesariamente separados de la norma jurídica. Esta separación conceptual entre lo moralmente bueno y las leyes formalmente escritas ocurre en sociedades occidentales-modernas, hecho que conduce a un cierto "legalismo", o lo que Max Weber (I978) llamó el "racionalismo jurídico formalista", el cual "determinó la aparición de la dominación de tipo legal, y que se vino a añadir a las diversas clases de dominación” (p. 52). Esta situación no solo es ajena a la tradición inga, sino que en estas comunidades no había una separación tajante entre los planos axiológico y ontológico (Rojas, 200I). Así, es entendible que una traducción en lengua inga tienda a coligar las leyes formales del Estado con conceptos autóctonos usados para designar lo bueno y lo malo en la cotidianidad.

\section{Reflexiones finales}

Hemos visto que los traductores son actores cuyas creaciones lingüísticas pueden dar forma a las representaciones que se difunden sobre la diversidad cultural, la sociedad mayoritaria, el Estado o sus instituciones. Esto, sin duda, puede influenciar las ideas que un grupo étnico se forma del otro, mediando así de manera importante en las relaciones que se establecen entre indígenas y la sociedad mayoritaria. Aunque desde el ideal interculturalista se hable, por ejemplo, de "aprender de otras culturas" o del "diálogo intercultural", no se debe ignorar que esa "interculturalidad" necesita traducciones que deben dejar de considerarse (particularmente por parte de los funcionarios bajo el régimen multiculturalista) como un simple requisito secundario que se supera mecánicamente a través de equivalencias directas entre un significante y otro. De la misma manera, traducir una ley tampoco puede considerarse simplemente como la transmisión de un conocimiento formal y "útil" para que los indígenas "conozcan sus derechos". La traducción implica trasladar una forma de ver el mundo y unos valores, y es siempre el resultado de un complejo "ensamblaje" (Latour, 2008) de símbolos, actores y condiciones sociales y materiales particulares.

Es clave, entonces, tener en cuenta el rol creativo de los traductores (incluyendo, por supuesto, a los traductores indígenas), así como el contexto amplio en que se encuentran: las representaciones sociales y las corrientes intelectuales (en buena medida globalizadas) que los influyen, los intereses económicos o políticos que los motivan, el tipo de relaciones que tienen con su comunidad y con otros sectores de la sociedad nacional o transnacional, etc. Es dentro de esa complejidad donde se difunden representaciones sobre el Estado y sus instituciones, sobre el "desarrollo", el "derecho" o el "bienestar", todo lo cual es particularmente problemático en contextos de relaciones asimétricas de poder y formas de subordinación históricamente constituidas. Lejos de ser un simple procedimiento técnico, la traducción en el marco de la interculturalidad es un conjunto de prácticas llevadas a cabo por individuos inmersos en juegos de poder y donde las relaciones nunca son "entre iguales".

Nada justifica, ya lo sabemos, que se imponga de nuevo una lengua colonizadora. Sin embargo, las traducciones no están exentas de influenciar o ser influenciadas por una u otra corriente hegemónica, o de favorecer los intereses de unos u otros, a veces de manera imprevista. El caso presentado acá muestra de manera clara que las mismas palabras o frases pueden ser traducidas de maneras muy diversas, que las traducciones no son neutras, que reproducen concepciones de la realidad particulares y que no se pueden desligar de momentos históricos y contextos sociales que van más allá de lo lingüístico e incluso de lo local. Sin pretender juzgar 
unas como mejores que otras (valga insistir que el objetivo acá no ha sido el de descalificar el arduo trabajo de quienes participaron en el proyecto de traducción de la Constitución Política), tampoco podemos negar los sesgos que tiene cualquiera de las traducciones, sesgos con fundamentos y consecuencias políticas innegables.

Los dilemas a los que se vieron enfrentados quienes tenían que traducir la Constitución, optando por una u otra estrategia, ponen en evidencia una contradicción profunda en las políticas multiculturalistas - y que está lejos de ser resuelta-, la cual plantea, por un lado, la autonomía de los grupos étnicos, pero, por el otro, la difusión de la Constitución como conjunto de leyes que deben ser impuestas en todo el país. Dicho de otro modo, el análisis de las formas lingüísticas que los traductores ingas consideraron necesarias para trasmitir los sentidos de la Constitución, nos lleva a preguntarnos hasta qué punto "culturas diferentes", como las indígenas, que supuestamente gozan de un cierto grado de autonomía, deben incorporar en su universo conceptual y en sus sistemas de valores (hacer suyo, hacer "entrar en su casa", domesticar, resignificar de acuerdo con referentes autóctonos) los conceptos y valores de la normatividad occidental. Mutatis mutandis, este es un dilema similar al que se descubre en los análisis sobre las posibilidades reales de que haya relaciones

\section{Referencias}

Aguirre, D. (1995). Recuperación cultural y problemas prácticos de la traducción: al rescate de la tradición cultural entre los Embera-Chamí de Antioquia. En CCELA (Ed.), Las lenguas aborígenes de Colombia. Memorias del Simposio: La recuperación de la Lenguas Nativas como búsqueda de la Identidad Étnica (pp. 19-38). Bogotá: Ediciones CCELA-Uniandes.

Barona, G. (2007). Falacias del pluralismo jurídico y cultural en Colombia: ensayo crítico. Popayán: Universidad del Cauca. "horizontales" entre las diferentes comunidades que coexisten dentro de un esquema de pluralismo jurídico (al respecto véanse, por ejemplo, Barona [2007] o Walsh [2012]). En el fondo, esto también se relaciona con la contradicción fundamental manifiesta en el lema político "unidad y diversidad". En el caso inga, como hemos visto, los traductores recurrieron a una estrategia que se inclina hacia un lado de esa dicotomía: la que privilegia la noción de unidad, la de asumir en la Constitución un "bien" común a todos los nacionales, la de asumir unos conceptos que deben ser compartidos por todos (y, por lo tanto, que debían corresponder con conceptos tradicionales ingas), la de imaginar un "territorio grande" que los incluye, la de construir discursivamente unas instituciones estatales y unas leyes que han de ser "buenas" para la gente en general.

En cuanto prácticas discursivas, las traducciones construyen los objetos mismos de los que hablan. Aunque pretendan ser usadas en el diálogo intercultural, es decir "entre iguales", las traducciones pueden favorecer (quizás inesperadamente para muchos) la difusión de ciertas ideas-valores o conceptos propios de una sociedad dominante y funcionales a un régimen. Por eso debemos mantener una mirada crítica respecto a las distintas acciones que se realizan bajo el multiculturalismo o en nombre de la "preservación de las culturas".

Bassnett, S. (2002). Translation studies. London: Routledge.

Brennan, T. (200I). The cuts of language: The east/west of north/south. Public Culture, 13(I), 39-63.

Centro Colombiano de Estudios de Lenguas Aborígenes (CCELA) (1994a). Constitución Política de Colombia de 1991 en Inga. Bogotá: CCELA-Universidad de Los Andes. 
Centro Colombiano de Estudios de Lenguas Aborígenes (CCELA). (1994b). Constitución Política de Colombia de 1991 en Kubeo. Bogotá: CCELA-Universidad de Los Andes.

Centro Colombiano de Estudios de Lenguas Aborígenes (CCELA). (I994c). Constitución Política de Colombia 1991 en Wayuunaiqui. Bogotá: CCELA-Universidad de Los Andes.

Centro Colombiano de Estudios de Lenguas Aborígenes (CCELA). (1987). Los significados de la educación bilingüe. Comisión en el Seminario sobre Lingüistica y Etnoeducación. Las Lenguas Aborígenes de Colombia, 1, 79-83.

Chaves, M. (20II). Presentación. En M. Chaves (Comp.), La multiculturalidad estatalizada. Indígenas, afrodescendientes y configuraciones de Estado (pp. 9-24). Bogotá: ICANH.

García-Canclini, N. (2005). Diferentes, desiguales $y$ desconectados. Mapas de la interculturalidad. Barcelona: Gedisa.

Graeber, D. (200I). Toward an anthropological theory of value. New York: Palgrave.

Graeber, D. (2005). Value: anthropological theories of value. En Carrier, J. (Ed.) A handbook of economic anthropology (pp. 439-454). Cheltenham: Edward Elgar Publishing.

Howland, D. (2003). The predicament of ideas in culture: Translation and historiography. History \& Theory, 42(I), 45-6o.

Jamioy, J. (I995). La lengua nativa es parte importante de la identidad indígena. En CCELA (Ed.), Las lenguas aborigenes de Colombia. Memorias del Simposio: La recuperación de la Lenguas Nativas como búsqueda de la Identidad Étnica (pp. 9-18). Bogotá: Ediciones CCELA-Uniandes.

Kamler, B., \& Threadgold, T. (2003). Translating Difference: questions of representation in cross-cultural research encounters. Journal of Intercultural Studies, 24(2), I37-I5I.

Landa, J. (2005). Entrar en otra casa. Gaceta del Fondo de Cultura Económica, 410, 2-4.

Landaburu, J. (1997a). Historia de la traducción de la Constitución de Colombia a siete lenguas indígenas (I992-1994). Amerindia, 22, I65-I76.
Landaburu, J. (1997b). Dificultades y logros de la traducción de la Constitución de Colombia. Amerindia, 22, Io9-II8.

Landaburu, J. (2004). La situación de las lenguas indígenas de Colombia: prolegómenos para una política lingüística viable. Amérique Latine Histoire et Mémoire. Les Cahiers ALHIM Recuperado de http://alhim.revues.org/I25

Latour, B. (2008). Reensamblar lo social: una introducción a la teoría del actor-red. Buenos Aires: Manantial.

Levinsohn, S., Mafla, A., \& Tandoy Chasoy, D. (1978). Diccionario inga del Valle de Sibundoy, Intendencia del Putumayo. Lomalinda, Perú: Editorial Townsend.

Oróstegui, S. (2008). Traducción de la Constitución colombiana de I99I a siete lenguas vernáculas. Reflexión Política, 10(I9), I64-I75

Paz, O. (I97I). Traducción: Literatura y literalidad. Barcelona: Tusquets.

Pineda, R. (1997). La Constitución de i991 y la perspectiva del multiculturalismo en Colombia. Alteridades, 7(14), I07-I29.

Rappaport, J. (2008). Utopías interculturales. Intelectuales públicos, experimentos con la cultura y pluralismo étnico en Colombia. Bogotá: Universidad del Rosario.

Rojas, T. (200I). Transportar la cosa hablada a otra lengua: la experiencia de la traducción de la Constitución de la República de Colombia a lenguas indígenas. En F. Castañeda y M. Vollet (Eds.), Concepciones de la conquista. Aproximaciones interdisciplinarias (pp. 36I388). Bogotá: Ediciones Uniandes.

Sarrazin, J. P. (20II). Du marxisme au chamanisme. Naissance d'un indigénisme local à l'heure globale. Saarbrücken:Éditions Universitaires Européennes. Spivak, G. (2000). The politics of translation. En L. Venuti (Ed.), The translation studies reader (pp. 83-II2). New York: Routledge.

Torres, A. (2002). La crisis de las equivalencias en la traducción. Bogotá: Uniandes (Colección Documentos del CESO, $\mathrm{N}^{\circ}$ I8). 
Walsh, C. (2012). El pluralismo jurídico: el desafío de la interculturalidad. Novamérica, 133, 32-37. Weber, M. (1978). Sociología de la religión. Buenos Aires: La Pléyade.

\section{Notas}

1. El texto analizado hizo parte del proyecto de traducción de la Constitución Política de Colombia de 1991 a siete lenguas indígenas (entre esas, la lengua inga), proyecto que el gobierno nacional encomendó al Centro Colombiano de Estudios de Lenguas Aborígenes de la Universidad de los Andes (CCELA).

2. Josu Landa utiliza esta metáfora de la traslación de una casa a otra para explicar la labor de todo traductor. Esta es la metáfora utilizada en el título del presente texto.

3. El texto original de la traducción no utiliza el alfabeto fonético internacional. Esto puede sorprender al especialista en lingüística, pero para los fines de este artículo, el alfabeto fonético internacional no es necesario.

4. A partir de las unidades significativas en inga traducidas al castellano, se encontraron los siguientes morfemas relativos al concepto bien: /bien/, /muy bien/, / bien-solamente/, /bien-afirmativa/, /buen/, /bueno/, / bueno-solamente/, /bonito-solamente/, /mejor/, /bienestar/. Posteriormente se encontró que estas unidades lingüísticas equivalían a las siguientes unidades en inga: /suma/, /sumaglla/, /sumagllami/, /alli/, /allilla/, /alliIlachu/. Para esta investigación, se analizaron todas las traducciones en las cuales hubiera cualquiera de las unidades significativas antes mencionadas. Según el Diccionario inga del valle del Sibundoy (Levinsohn, Mafla \& Tandoy Chasoy, 1978), la unidad /suma/ corresponde a un adverbio que denotan: "bonito, hermoso, simpático, atrayente, bueno"; la partícula /g/ denota: "apreciativo o un poco despectivo"; la partícula /lla/ aparece con los adverbios y precede a los verbos; la unidad /alli/ corresponde a una adverbio que denota "bueno, bien"; la unidad /allilla/ corresponde a "bien" (exclamativo), "buenos días" (exclamativo); y /allillachu/ corresponde a "está bien" (saludo antiguo).

5. En esta sección no necesariamente se presenta la totalidad de cada uno de los artículos, sino únicamente algunas de sus partes más relevantes para este estudio. 